\title{
Treatment of malignant pleural mesothelioma with chemotherapy preceding versus after surgical resection
}

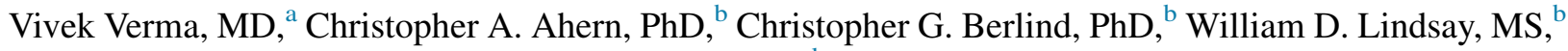
Surbhi Grover, MD, MPH, ${ }^{\mathrm{c}}$ Joseph S. Friedberg, MD, ${ }^{\mathrm{d}}$ and Charles B. Simone II, MD

\section{ABSTRACT}

Objectives: There are 2 main treatment paradigms recognized by the National Comprehensive Cancer Network for resectable malignant pleural mesothelioma (MPM): induction chemotherapy followed by resection (IC/R), and up-front resection with postoperative chemotherapy (R/PC). These paradigms are being compared in an accruing randomized phase II trial. In the absence of such completed trials, in this study we evaluated overall survival (OS) and postoperative outcomes of IC/R and R/PC.

Methods: The National Cancer Database was queried for newly diagnosed epithelioid/biphasic MPM. Metastatic, node-positive, and/or cT4 disease was excluded, along with nondefinitive surgery and lack of chemotherapy. Multivariable logistic regression ascertained factors independently associated with induction chemotherapy delivery. Kaplan-Meier analysis was used to evaluate OS between cohorts; multivariable Cox proportional hazards modeling was used to assess factors associated with OS. Survival was also evaluated between propensity-matched populations. Last, postoperative outcomes were assessed between groups.

Results: Overall, 361 patients (182 IC/R, 179 R/PC) were analyzed. Temporal trends revealed that IC/R is decreasing over time. Survival of the IC/R cohort was similar to that of R/PC patients (20.9 vs 21.7 months; $P=.500)$; this persisted after propensity matching ( 20.8 vs 22.0 months; $P=.270)$. However, patients who underwent IC/R experienced longer postoperative hospitalization (median 7 days vs 6 days; $P=.001)$ and higher 30 -day mortality $(3.3 \%$ vs $0 \% ; P=.020)$.

Conclusions: To our knowledge, this is the only comparative investigation of the 2 major management paradigms of operable MPM. IC/R regimens are decreasing over time in the United States. Although associated with survival similar to R/PC, $\mathrm{IC} / \mathrm{R}$ might be associated with worse postoperative outcomes. Careful induction chemotherapy patient selection is thus highly recommended. (J Thorac Cardiovasc Surg 2019;157:758-66)

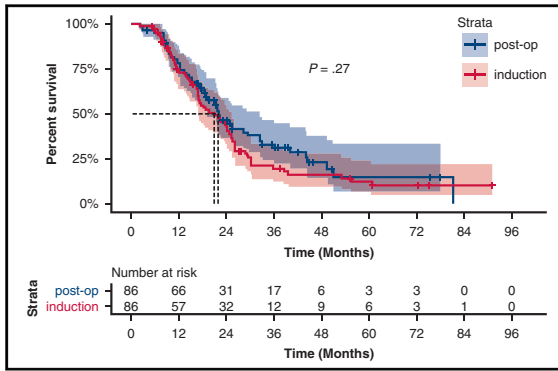

Overall survival after propensity matching between IC/R and $\mathrm{R} / \mathrm{PC}$.

\section{Central Message}

For operable MPM, induction chemotherapy is associated with similar survival but worse postoperative outcomes with up-front resection.

\section{Perspective}

Operable MPM is treated with induction chemotherapy followed by resection (IC/R), or up-front resection with postoperative chemotherapy (R/PC). This is the only known comparative study of these paradigms, which shows similar survival but worse postoperative outcomes with IC/R.

See Editorial Commentary page 767.
Although relatively uncommon, malignant pleural mesothelioma (MPM) is a highly aggressive malignancy

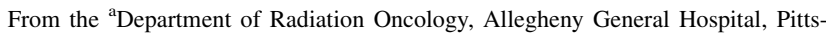
burgh, $\mathrm{Pa} ;{ }^{\mathrm{b}}$ Oncora Medical, Philadelphia, Pa; ${ }^{\mathrm{c}}$ Department of Radiation Oncology, University of Pennsylvania, Philadelphia, Pa; ${ }^{\mathrm{d}}$ Division of Thoracic Surgery, Department of Surgery, and ${ }^{\mathrm{e}}$ Department of Radiation Oncology, University of Maryland Medical Center, Baltimore, Md.

Received for publication May 5, 2018; revisions received Sept 19, 2018; accepted for publication Oct 8, 2018; available ahead of print Nov 16, 2018.

Address for reprints: Charles B. Simone II, MD, University of Maryland School of Medicine, Department of Radiation Oncology, Maryland Proton Treatment Center, 850 W Baltimore St, Baltimore, MD 21201 (E-mail: charlessimone@umm.edu). $0022-5223 / \$ 36.00$

Copyright (c) 2018 by The American Association for Thoracic Surgery

https://doi.org/10.1016/j.jtcvs.2018.10.039 associated with a very poor prognosis. As a result, management requires strong multimodality coordination between surgical, medical, and radiation oncologists. ${ }^{1}$ The standard of care for resectable, nonmetastatic MPM centers on a combination of gross macroscopic resection (with or without intraoperative therapy), chemotherapy, and postoperative radiotherapy in select cases. ${ }^{1-6}$

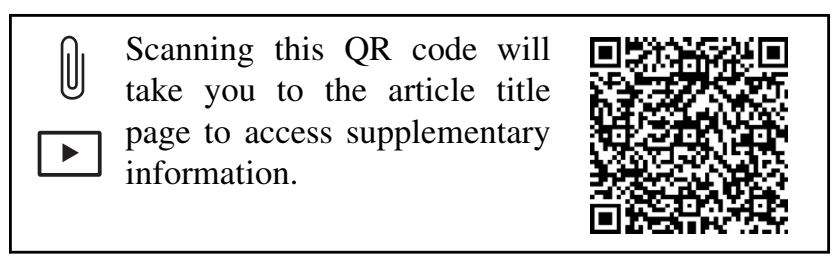




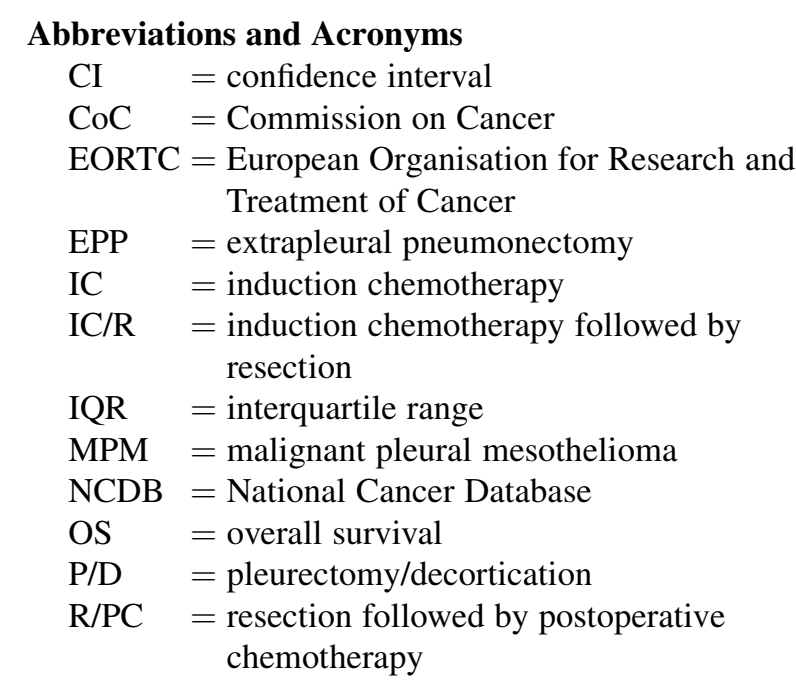

However, considerably less characterized is the optimal sequencing of therapy. The National Comprehensive Cancer Network outlines 2 major approaches to the multimodality treatment of MPM: induction chemotherapy (IC) followed by resection (IC/R) or resection followed by postoperative chemotherapy (R/PC). Both of these approaches have been well studied and offer unique advantages and disadvantages. Administering IC (which more optimally delivers full-dose chemotherapy than in the adjuvant setting) might allow for tumor downstaging or even rare cases of complete response, ${ }^{7,8}$ thus increasing the likelihood of resectability and/or the amount of gross debulking. IC might also offer more refined surgical selection on the basis of tumor biology; because progression during chemotherapy is a poor prognostic factor, those patients who progress during IC are not expected to have favorable outcomes after surgery and might be spared of surgical morbidities. ${ }^{9}$ Conversely, MPM responds to IC suboptimally in most cases,${ }^{10}$ and it also carries morbidity risks that might preclude (or delay) patients from receiving surgical resection or trimodality therapy. ${ }^{11}$ It might also be associated with increased surgical complications, as evidenced in institutional as well as prospective studies. ${ }^{10-15}$

Hence, IC/R versus $\mathrm{R} / \mathrm{PC}$ is a highly controversial issue and very often debated in multidisciplinary settings. For this reason, the European Organisation for Research and Treatment of Cancer (EORTC) is conducting a randomized phase II trial comparing IC/R and R/PC. ${ }^{16}$ This currently accruing trial uses 3 cycles of cisplatin/pemetrexed chemotherapy, pleurectomy/decortication (P/D) surgical technique (Video 1), has an estimated enrollment of 64 patients, and has a primary end point of "treatment success" (encompassing tolerance of therapy, toxicities, and relapse-related outcomes). In the absence of randomized data, there currently are no known retrospective data on outcomes of both

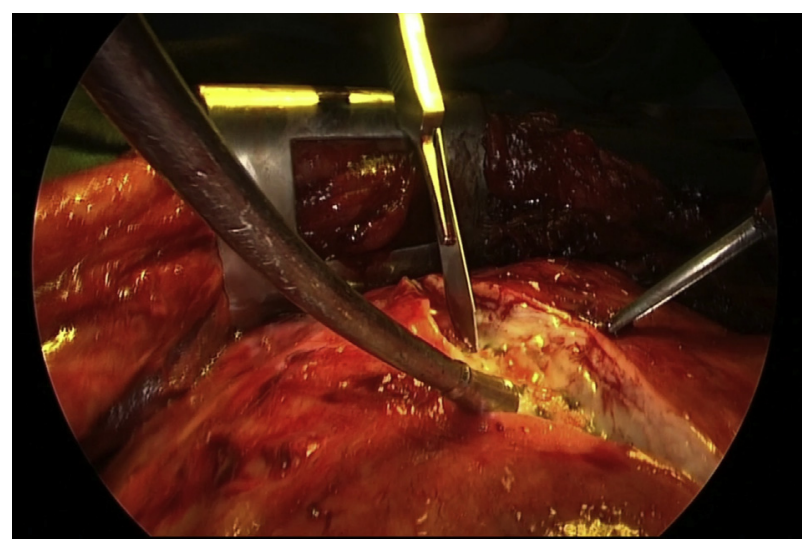

VIDEO 1. This video clip depicts the extended pleurectomy technique for malignant pleural mesothelioma. By this point in the operation, the tumor has been mobilized off the chest wall, diaphragm, and anterior/posterior/superior mediastinum to the pulmonary hilum. The cancer is now completely mobilized and tethered solely to the lung. Using a split ventilation technique, with the nonoperative lung being ventilated normally and the operative lung being placed on constant positive pressure, the cancer is now removed, enbloc, with the entire visceral pleura. This clip starts with an incision of the chest wall surface of the tumor being divided through the visceral pleura and concludes with the mobilized tumor being divided down to the posterior pulmonary hilum, where the aorta and spine now come into view. Subsequent to this clip, the tumor is liberated circumferentially around the hilum, allowing it to be removed from the chest. Video available at: https://www.jtcvs. org/article/S0022-5223(18)32793-4/fulltext.

approaches. The goal of this novel investigation of a contemporary national database, the largest to date, was to evaluate practice patterns, trends, and outcomes (overall survival $[\mathrm{OS}]$ and postoperative events) for both approaches.

\section{METHODS}

The National Cancer Database (NCDB) is a joint project of the Commission on Cancer $(\mathrm{CoC})$ of the American College of Surgeons and the American Cancer Society that consists of information regarding tumor characteristics, patient demographic characteristics, and patient survival for approximately $70 \%$ of the United States population. ${ }^{17}$ The NCDB contains information that is not included in the Surveillance, Epidemiology, and End Results database, including details regarding use of systemic therapy. The data used in this study were derived from a deidentified NCDB file. The American College of Surgeons and the $\mathrm{CoC}$ have not verified and are neither responsible for the analytic or statistical methodology used nor the conclusions drawn from these data. Because all patient information in the NCDB database is deidentified, this study was exempt from institutional review board evaluation.

The NCDB Participant User File corresponding to mesothelioma (20042012) was used for this study. Inclusion criteria for this investigation were patients with newly diagnosed MPM who received chemotherapy and definitive surgery (extrapleural pneumonectomy $[\mathrm{EPP}]$ or $\mathrm{P} / \mathrm{D}^{18,19}$ ). Because surgical resection is generally not recommended (and rarely performed) for sarcomatoid, node-positive, and/or clinical T4 disease, these constituted exclusion criteria. Patients without proper Tumor, Node, Metastases staging were also eliminated, as were metastatic and palliative care patients (as designated in the NCDB). In accordance with the variables in NCDB files, information collected on each patient broadly included demographic, clinical, and treatment data. Patients were divided into groups on the basis of whether chemotherapy started before resection (IC/R) or after resection (R/PC). 
Statistical analysis was performed with $\mathrm{R} .{ }^{20}$ Tests were 2 -sided, with a threshold of $P<.05$ for statistical significance. First, clinical characteristics between both cohorts were tabulated. Multivariable logistic regression analysis was performed to ascertain factors independently associated with delivery of IC. Kaplan-Meier curves were calculated to evaluate OS, defined as the interval between the date of diagnosis and the date of death, or censored at last contact. Multivariable Cox proportional hazards modeling was used to evaluate predictors of OS. In an attempt to minimize selection and indication biases, patients in both cohorts underwent propensity matching (Table E1). To estimate the propensity score for each patient, the univariate association of each covariate with treatment type was assessed using a simple logistic regression model. Covariates that were significantly associated with treatment type $(P<.05)$ were included in a multivariable logistic regression model. One-to-one matching was performed using a "greedy" nearest neighbor algorithm with a caliper 0.2 times the standard deviation of the logit propensity score. ${ }^{21,22}$ The standardized difference between groups after matching was $<0.1$, indicating sufficient balancing. ${ }^{23}$ Propensity matching took into account all variables (listed in Table 1) except radiotherapy. Kaplan-Meier curves were then calculated on the propensity matched patients.

Last, because the NCDB codes for 4 postoperative outcomes (30-day readmission, 30- and 90-day mortality, length of postoperative hospital stay), these were evaluated according to treatment group in the overall population. The $\chi^{2}$ test was used to compare readmission and mortality proportions, and the Mann-Whitney $U$ test for postoperative hospitalization. These comparisons were only performed for the unmatched population, because propensity matching was designed to evaluate OS and not intended to match for other end points.

\section{RESULTS}

A patient selection diagram is illustrated in Figure 1. In total, 361 patients met study criteria; this included 182 $(50 \%)$ patients who underwent IC/R and $179(50 \%)$ who received R/PC. Figure 2 shows that the IC/R paradigm is decreasing over time.

Table 1 shows notable clinical characteristics of each cohort. Most patients were Caucasian, male, and lived in a metro area. In multivariable logistic regression analysis, groups were overall relatively balanced with a few exceptions. More recent time periods were associated with less use of IC/R $(P<.001)$. Additionally, there were regional differences in treatment paradigms. Compared with east north central states (Ill, Ind, Mich, Ohio, Wis), IC/R was more frequently used in the middle and south Atlantic, Mountain, west north central, and Pacific regions $(P<.05$ for all). IC/R was more often delivered at academic centers and to patients living farther from the facility $(P<.05$ for both). Of note, there were no differences on the basis of $\mathrm{T}$ or $\mathrm{N}$ classification, histology, age, or Charlson comorbidity index $(P>.05$ for all).

Median follow-up was 19 months (interquartile range [IQR], 11-29 months). Kaplan-Meier estimates comparing OS in various cohorts are illustrated in Figure 3. Survival of the IC/R cohort (median 20.9 months; $95 \%$ confidence interval $[\mathrm{CI}], 18.9-23.7$ months) was similar to that of R/PC patients (median 21.7 months; 95\% CI, 19.3-25.3 months; $P=.500$; Figure $3, A$ ). After propensity matching, similarities in OS between groups persisted (median 20.8 (95\% CI
16.9-25.3) months vs. 22.0 (95\% CI 19.9-32.4) months, respectively, $P=.270$, Figure $3, B)$. Of note, when considering only $\mathrm{P} / \mathrm{D}$ patients, there were no OS differences between IC/R and R/PC $(P=.900$; Figure $3, C)$; however, in the EPP subset, there was a nonsignificant trend toward higher OS in R/PC patients $(P=.074$; Figure $3, D)$.

In the overall (prematched) cohort, when adjusting for potential confounders, there were several predictors of OS in multivariable analysis (Table 2). Factors independently predictive of poorer OS were advanced age $(P<.001)$, treatment at a community center $(P=.002)$, and advanced $\mathrm{T}$ classification $(P<.001)$. Improved OS was associated with epithelioid histology and higher household income $(P<.05$ for both). Of note, receipt of IC/R was associated with poorer $\operatorname{OS}(P=.030)$ in multivariable analysis, despite the findings in Figure 3 before and after matching.

Last, postoperative outcomes were compared between both cohorts. The 30-day mortality for the R/PC group was $0.0 \%$, compared with $3.3 \%$ for the IC/R cohort $(P=.020)$. Figures for 90 -day mortality were statistically similar between cohorts $(7.1 \%$ for IC/R vs $2.8 \%$ for $\mathrm{R} /$ $\mathrm{PC} ; P=.104)$. Patients who received $\mathrm{R} / \mathrm{PC}$ experienced shorter length of postoperative hospitalization (median, 6; IQR, 4-8 days) than those who underwent IC/R (median, 7; IQR, 5-9 days; $P=.001$ ). There were no differences between groups in 30 -day readmission rates $(5.0 \%$ for IC/R; $3.8 \%$ for R/PC; $P=.544)$. Substratification of the overall cohort into EPP and P/D groups was next performed; for EPP patients, there were no differences between IC/R and $\mathrm{R} / \mathrm{PC}$ in any of the 4 parameters $(P=.300$ for 30 -day mortality; $P=.092$ for 90 -day mortality; $P=.773$ for postoperative hospitalization; $P=.568$ for 30 -day readmission). For the P/D subset, there were trends for higher 30$(P=.087)$ and 90 -day mortality $(P=.060)$ in the IC/R group. Additionally, 30-day readmission rates were similar $(P=.113)$, but there was longer postoperative hospitalization in the IC/R group $(P=.003)$.

\section{DISCUSSION}

Although there are no known studies to date evaluating the 2 main paradigms for operable MPM management, this novel investigation of a large, contemporary national database illustrates several key points. First, the use of IC/ $\mathrm{R}$ in the United States is decreasing over time. In addition to time period, there were several factors associated with delivery of IC, such as regional- and facility-related differences. In the nonmatched and matched populations, IC/R and R/PC were associated with similar OS. However, patients who received IC were shown to experience statistically longer postoperative hospitalization and higher 30-day mortality.

This large study addresses an important issue for which no comparative studies (prospective or retrospective) exist to date in the literature, and these findings have notable 
TABLE 1. Characteristics of the overall cohort and significant factors associated with receiving induction chemotherapy followed by resection

\begin{tabular}{|c|c|c|c|c|}
\hline \multirow[b]{2}{*}{ Parameter } & \multirow[b]{2}{*}{ IC/R $(n=182)$} & \multirow[b]{2}{*}{$\mathbf{R} / \mathbf{P C}(\mathbf{n}=\mathbf{1 7 9})$} & \multicolumn{2}{|c|}{ Multivariable } \\
\hline & & & OR $(95 \%$ CI $)$ & $P$ value \\
\hline \multicolumn{5}{|l|}{ Age, y } \\
\hline Median (IQR) & $66(59-71)$ & $68(62-75)$ & $0.96(0.923-1.010)$ & .102 \\
\hline \multicolumn{5}{|l|}{ Sex } \\
\hline Male & $148(81)$ & $143(80)$ & $1.35(0.659-2.780)$ & .413 \\
\hline Female & $34(19)$ & $36(20)$ & REF & REF \\
\hline \multicolumn{5}{|l|}{ Race } \\
\hline White & $172(95)$ & $170(95)$ & $1.91(0.384-10.700)$ & .437 \\
\hline Black & $5(3)$ & $5(3)$ & REF & REF \\
\hline Other & $2(1)$ & $2(1)$ & $2.57(0.257-49.100)$ & .516 \\
\hline Unknown & $3(1)$ & $2(1)$ & & \\
\hline \multicolumn{5}{|c|}{ Charlson Deyo comorbidity index } \\
\hline 0 & $143(79)$ & $130(73)$ & REF & REF \\
\hline 1 & $36(20)$ & $37(21)$ & $1.30(0.639-2.670)$ & .470 \\
\hline$\geq 2$ & $3(1)$ & $12(7)$ & $0.48(0.090-1.960)$ & .337 \\
\hline \multicolumn{5}{|l|}{ Insurance type } \\
\hline Private & $88(48)$ & $71(40)$ & $1.94(0.318-3.905)$ & .412 \\
\hline Medicare & $85(47)$ & $101(56)$ & $0.80(0.229-1.466)$ & .382 \\
\hline Medicaid & $0(0)$ & $3(2)$ & REF & REF \\
\hline Other government & $4(2)$ & $0(0)$ & & \\
\hline Uninsured & $0(0)$ & $1(1)$ & & \\
\hline Unknown & $5(3)$ & $3(2)$ & & \\
\hline \multicolumn{5}{|l|}{ Income, USD per year } \\
\hline$<\$ 30,000$ & $15(8)$ & $13(7)$ & REF & REF \\
\hline$\$ 30,000-\$ 34,999$ & $33(18)$ & $28(16)$ & $1.61(0.523-4.990)$ & .408 \\
\hline$\$ 35,000-\$ 45,999$ & $46(25)$ & $45(25)$ & $2.22(0.676-7.510)$ & .192 \\
\hline$\geq \$ 46,000$ & $86(47)$ & $92(51)$ & $5.00(1.390-18.800)$ & .015 \\
\hline Unknown & $2(1)$ & $1(1)$ & & \\
\hline \multicolumn{5}{|c|}{$\begin{array}{l}\text { Percentage of adults in zip code } \\
\text { without high school diploma }\end{array}$} \\
\hline$\geq 21 \%$ & $13(7)$ & $10(6)$ & REF & REF \\
\hline $13 \%-20.9 \%$ & $44(24)$ & $38(21)$ & $0.99(0.291-3.390)$ & .995 \\
\hline $7 \%-12.9 \%$ & $72(40)$ & $59(33)$ & $0.70(0.194-2.430)$ & .574 \\
\hline$<7 \%$ & $51(28)$ & $71(40)$ & $0.23(0.055-0.916)$ & .040 \\
\hline Unknown & $2(1)$ & $1(1)$ & & \\
\hline \multicolumn{5}{|l|}{ Patient residence } \\
\hline Metro & $152(84)$ & $157(88)$ & REF & REF \\
\hline Rural & $4(2)$ & $2(1)$ & $1.48(0.180-15.700)$ & .723 \\
\hline Urban & $22(12)$ & $15(8)$ & $2.53(0.916-7.200)$ & .076 \\
\hline Unknown & $4(2)$ & $5(3)$ & & \\
\hline \multicolumn{5}{|l|}{ Facility location } \\
\hline East north central & $19(10)$ & $52(29)$ & REF & REF \\
\hline East south central & $4(2)$ & $10(6)$ & $2.80(0.565-12.300)$ & .183 \\
\hline Middle Atlantic & $49(27)$ & $49(27)$ & $2.78(1.240-5.135)$ & .014 \\
\hline Mountain & $6(3)$ & $3(2)$ & $27.1(4.750-190.287)$ & $<.001$ \\
\hline New England & $2(1)$ & $14(8)$ & $0.40(0.049-2.170)$ & .332 \\
\hline Pacific & $30(16)$ & $16(9)$ & $5.50(2.050-15.511)$ & $<.001$ \\
\hline South Atlantic & $51(28)$ & $24(13)$ & $9.64(3.920-25.172)$ & $<.001$ \\
\hline West north central & $11(6)$ & $7(4)$ & $6.29(1.790-23.706)$ & .005 \\
\hline West south central & $4(2)$ & $3(2)$ & $0.94(0.047-15.102)$ & .967 \\
\hline Unknown & $6(3)$ & $1(1)$ & & \\
\hline \multicolumn{5}{|l|}{ Facility type } \\
\hline Academic & $140(77)$ & $108(60)$ & REF & REF \\
\hline
\end{tabular}


TABLE 1. Continued

\begin{tabular}{|c|c|c|c|c|}
\hline \multirow[b]{2}{*}{ Parameter } & \multirow[b]{2}{*}{$\operatorname{IC} / \mathbf{R}(n=182)$} & \multirow[b]{2}{*}{$\mathrm{R} / \mathrm{PC}(\mathbf{n}=\mathbf{1 7 9})$} & \multicolumn{2}{|c|}{ Multivariable } \\
\hline & & & OR $(95 \%$ CI $)$ & $P$ value \\
\hline Community & $36(20)$ & $70(40)$ & $0.39(0.190-0.764)$ & .007 \\
\hline Unknown & $6(3)$ & $1(1)$ & & \\
\hline \multicolumn{5}{|c|}{ Distance to treating facility, miles } \\
\hline Median (IQR) & $28(11-88)$ & $12(6-29)$ & $1.01(1.001-1.010)$ & .004 \\
\hline \multicolumn{5}{|l|}{ Year of diagnosis } \\
\hline 2004-2008 & $70(38)$ & $30(17)$ & REF & REF \\
\hline 2009-2012 & $112(62)$ & $149(83)$ & $0.703(0.606-0.808)$ & $<.001$ \\
\hline \multicolumn{5}{|l|}{ Clinical $\mathrm{T}$ classification } \\
\hline T0 & $0(0)$ & $1(1)$ & REF & REF \\
\hline $\mathrm{T} 1$ & $57(31)$ & $72(40)$ & $1.16(0.219-1.193)$ & .989 \\
\hline $\mathrm{T} 2$ & $80(44)$ & $67(37)$ & $1.41(0.268-2.063)$ & .969 \\
\hline $\mathrm{T} 3$ & $45(25)$ & $39(22)$ & $1.49(0.281-2.168)$ & .961 \\
\hline \multicolumn{5}{|l|}{ Histology } \\
\hline Biphasic & $30(16)$ & $45(25)$ & $0.58(0.282-1.150)$ & .121 \\
\hline Epithelioid & $152(84)$ & $134(75)$ & REF & REF \\
\hline \multicolumn{5}{|c|}{$\begin{array}{l}\text { Time from diagnosis to initial } \\
\text { treatment, } d\end{array}$} \\
\hline Median (IQR) & $35(19-48)$ & $30(0-64)$ & $*$ & * \\
\hline \multicolumn{5}{|l|}{ Surgical technique } \\
\hline EPP & $69(38)$ & $36(20)$ & * & $*$ \\
\hline $\mathrm{P} / \mathrm{D}$ & $113(62)$ & $143(80)$ & $*$ & $*$ \\
\hline \multicolumn{5}{|c|}{ Receipt of radiation therapy } \\
\hline Yes & $67(37)$ & $28(16)$ & * & $*$ \\
\hline No & $114(63)$ & $150(84)$ & * & * \\
\hline Unknown & $1(1)$ & $1(1)$ & & \\
\hline
\end{tabular}

implications because the EORTC randomized trial is currently accruing. Its retrospective nature does not imply causation and might be associated with selection biases; however, these biases might either favor or disfavor either group. For instance, as mentioned before, the IC/R patients included in this study received resection, implying that progressors during IC (who likely would not have undergone surgery ${ }^{9}$ ) were removed. This is similar to patient selection for the ongoing EORTC trial, ${ }^{16}$ and might "enrich" the IC/ $\mathrm{R}$ population on the basis of more favorable tumor biology. However, conversely, the IC population might have had a larger volume of disease burden that might have required IC and/or have been unresectable up-front. To this extent, it lends credence to this study that both groups were relatively balanced in terms of clinical variables in multivariable logistic regression, including age, sex, comorbidity index, T classification, and histology.

Although it is noteworthy that IC/R is decreasing in the United States over time, IC-based regimens have long been used in Europe. ${ }^{10,12,13,15}$ Although particular reasons for the decline in the United States remain unclear, it was apparent in multivariable logistic regression analysis that even within the United States there are notable geographic differences in terms of delivering chemotherapy preoperatively or postoperatively, along with differences according to whether the treating facility was an academic or community center.

It should be further explained why IC/R was associated with OS in Cox multivariable analysis, but not so in Kaplan-Meier analysis before and after propensity matching. Multivariable analysis cannot account for unforeseen biases as mentioned previously, such as likelihood of occult metastatic disease or volume of disease. The latter could explain why a greater proportion of patients in the IC cohort underwent EPP as opposed to P/D. Additionally, it is difficult to ascribe OS to treatment effect in multivariable analysis when a univariable comparison in unmatched KaplanMeier analysis was not statistically significant. Propensity matching is a considerably more robust measure with which to address unrecognized biases than multivariable modeling, and as a result, the nonsignificant findings between cohorts after matching lend support to the finding 


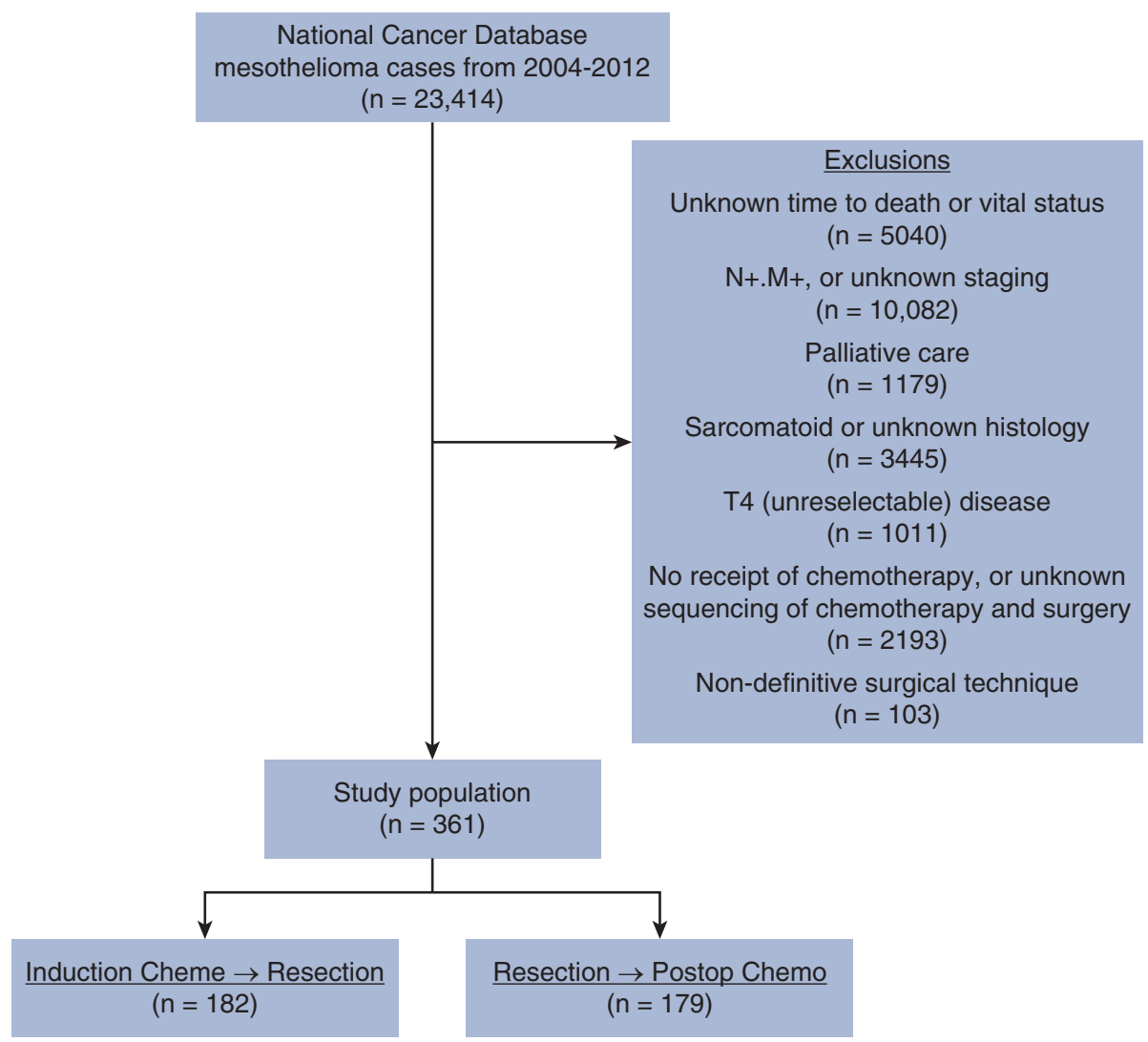

FIGURE 1. Patient selection diagram. Chemo, Chemotherapy; Postop, postoperative.

that order of chemotherapy and resection might not affect OS. This issue remains without definitive answers, however, not only because this is a retrospective investigation, but also because the NCDB does not record the number of cycles, doses, or agents of chemotherapy. Nevertheless, the survival outcomes herein mirror those of a systematic

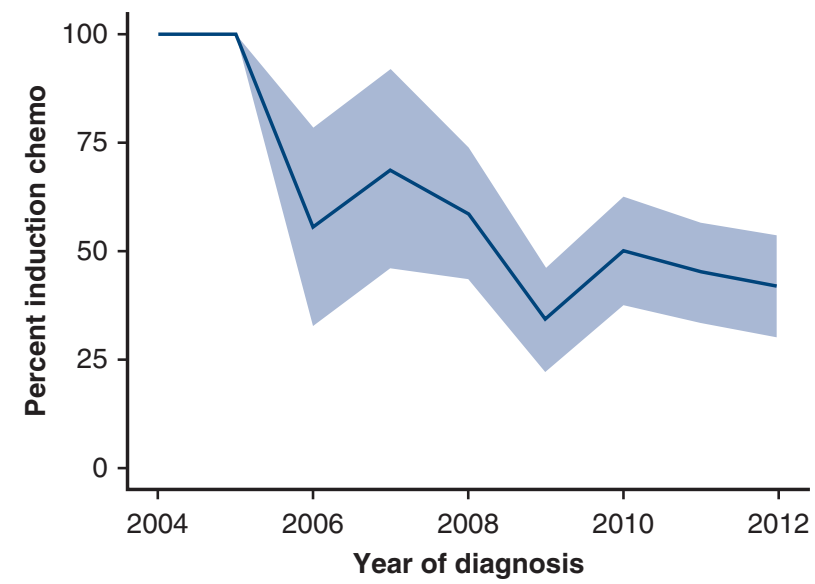

FIGURE 2. Temporal trends in induction chemotherapy use. Shaded area represents $95 \%$ confidence intervals. Chemo, Chemotherapy. review published in 2017 evaluating all known studies of IC and postoperative chemotherapy. ${ }^{24}$ Although no metaanalysis was performed, median OS figures are approximately comparable between both groups therein (and to the values in this study), largely because of the wide range reported from study to study.

Next, the finding of postoperative morbidity/mortality being more pronounced in the IC/R cohort is consistent with many investigations, even though the respective 30 - and 90-day mortality values of $3.3 \%$ and $7.1 \%$ are numerically favorable in most studies. For instance, the perioperative (30-day) mortality in the SAKK study was $4.0 \%$, and it was $6.5 \%$ to $7.0 \%$ in 2 multicenter trials from the United States and the EORTC. ${ }^{13-15}$ Other reports (including the Mesothelioma and Radical Surgery trial) have observed rates as high as $11 \% \cdot{ }^{10,11}$ One explanation for the lower perioperative mortality in this study is that IC patients were likely well selected (especially because its use is declining in the United States), unlike many of the aforementioned prospective studies. Another rationale is that we did not stratify postoperative outcomes according to EPP versus $\mathrm{P} / \mathrm{D}$, which was not statistically feasible because of the relatively low number of perioperative mortality events. Nevertheless, it is also 

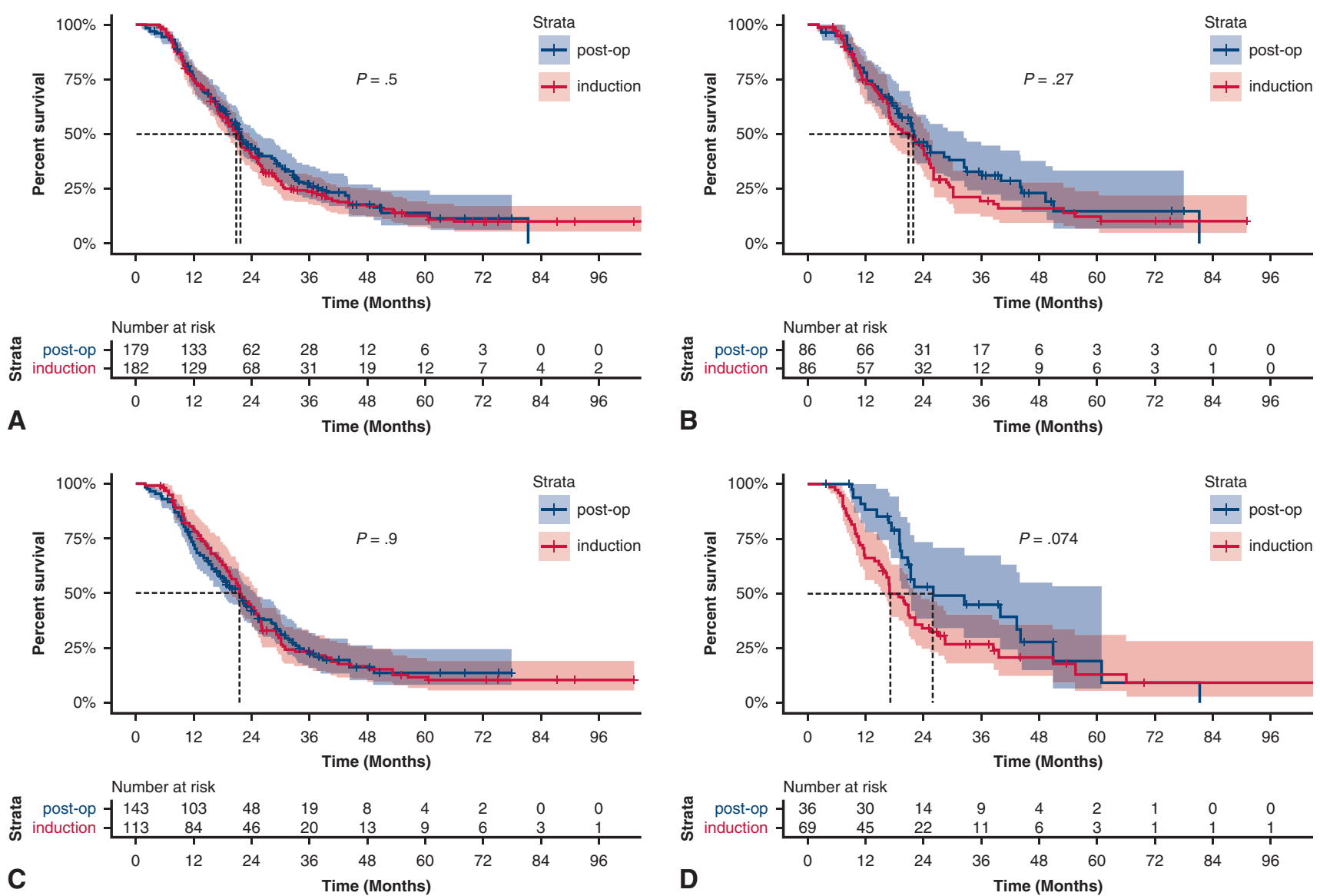

C

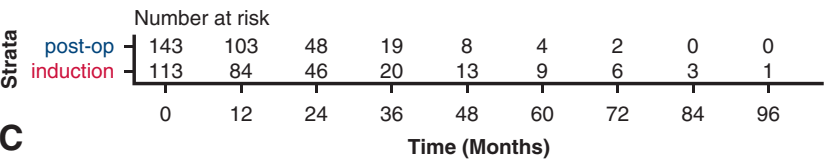

FIGURE 3. A, Overall survival according to treatment group for the entire cohort. B, Overall survival in the propensity score-matched population. Shaded areas represent $95 \%$ confidence intervals. C, Overall survival according to treatment group in patients having undergone pleurectomy/decortication. D, Overall survival according to treatment group in patients having undergone extrapleural pneumonectomy. post-op, Postoperative.

notable that, unlike some studies, ${ }^{11}$ IC did not seem to impair receipt of adjuvant radiotherapy; in fact, patients in the IC group were more likely to undergo adjuvant radiotherapy $\left(\chi^{2} P<.001\right)$, likely because more patients in that cohort received EPP $\left(\chi^{2} P<.001\right)$.

Although the NCDB provides a unique data source with which to study this controversial clinical question, NCDB studies have several limitations. ${ }^{25-33}$ In addition to the aforementioned caveats of a retrospective study as well as the lack of chemotherapy-related information, the NCDB does not provide information on extent of resection (eg, gross macroscopic) and/or tumor response to IC. Next, although the NCDB includes data for $70 \%$ of the United States population, only $\mathrm{CoC}$-accredited facilities contribute data (and the final study population comprised approximately $2 \%$ of the entire database). As such, these findings might not necessarily be representative of the entire United States population. It was also not possible to add another substratification for facility volume, recognizing that highvolume centers are associated with fewer postoperative complications. ${ }^{19,34,35}$ Additionally, because of the smaller sample sizes in this study, it was not possible to perform a "complete" propensity match for every possible variable to the greatest possible extent on account of sharply reducing sample size when doing so. Last, the NCDB does not track several noteworthy variables, such as performance status, pulmonary function tests, and salvage therapies, all which could affect OS and confound propensity matching and conclusions of the current study. It also does not record other end points, such as tolerance of therapy (including premature cessation of chemotherapy and/or radiotherapy), potentially further enriching the IC/R population because we only included patients who went on to have surgery after IC. The NCDB also does not provide data on cancer-specific survival, local/regional control, or specific causes of postoperative morbidity and/or mortality. Nevertheless, the results of the ongoing EORTC study are eagerly anticipated to verify the conclusions herein.

\section{CONCLUSIONS}

To our knowledge, this is the only known study of its kind to date; this investigation of a large, contemporary national 
TABLE 2. Multivariable Cox proportional hazards model for overall survival

\begin{tabular}{|c|c|c|}
\hline Parameter & HR $(95 \%$ CI $)$ & $P$ value \\
\hline Age (continuous) & $1.045(1.020-1.070)$ & $<.001$ \\
\hline Sex (male vs female) & $1.020(0.664-1.568)$ & .927 \\
\hline \multicolumn{3}{|l|}{ Race (reference: black) } \\
\hline White & $0.066(0.246-1.776)$ & .412 \\
\hline Other & $0.472(0.147-1.737)$ & .208 \\
\hline \multicolumn{3}{|c|}{ Charlson Deyo score (reference: 0) } \\
\hline 1 & $1.032(0.743-1.433)$ & .852 \\
\hline 2 & $0.954(0.503-1.809)$ & .886 \\
\hline \multicolumn{3}{|l|}{$\begin{array}{l}\text { Insurance status (reference: } \\
\text { Medicaid) }\end{array}$} \\
\hline Medicare & $0.921(0.322-2.441)$ & .879 \\
\hline Uninsured & $1.154(0.362-3.843)$ & .868 \\
\hline Other government & $0.382(0.089-1.761)$ & .193 \\
\hline Private & $1.025(0.356-3.062)$ & .967 \\
\hline \multicolumn{3}{|c|}{$\begin{array}{l}\text { Income (reference: first [bottom] } \\
\text { quartile) }\end{array}$} \\
\hline Second quartile & $0.710(0.392-1.285)$ & .257 \\
\hline Third quartile & $0.509(0.277-0.936)$ & .030 \\
\hline Fourth quartile & $0.574(0.302-1.090)$ & .090 \\
\hline \multicolumn{3}{|c|}{$\begin{array}{l}\text { Percentage of adults in zip code } \\
\text { without high school diploma } \\
\text { (reference: } \geq 21 \% \text { ) }\end{array}$} \\
\hline $13 \%-20.9 \%$ & $0.775(0.400-1.501)$ & .450 \\
\hline $7 \%-12.9 \%$ & $1.342(0.679-2.652)$ & .398 \\
\hline$<7 \%$ & $1.066(0.528-2.156)$ & .858 \\
\hline \multicolumn{3}{|c|}{ Patient residence (reference: metro) } \\
\hline Rural & $0.590(0.240-1.449)$ & .250 \\
\hline Urban & $1.146(0.663-1.980)$ & .627 \\
\hline \multicolumn{3}{|c|}{$\begin{array}{l}\text { Facility location (reference: east } \\
\text { north central) }\end{array}$} \\
\hline East south central & $1.302(0.661-2.567)$ & .446 \\
\hline Middle Atlantic & $0.720(0.486-1.067)$ & .102 \\
\hline Mountain & $0.339(0.142-0.807)$ & .014 \\
\hline New England & $0.767(0.410-1.432)$ & .404 \\
\hline Pacific & $0.752(0.461-1.227)$ & .254 \\
\hline South Atlantic & $0.743(0.476-1.159)$ & .191 \\
\hline West north central & $0.510(0.231-1.124)$ & .095 \\
\hline West south central & $0.637(0.261-1.556)$ & .323 \\
\hline $\begin{array}{l}\text { Facility type (community vs } \\
\text { academic) }\end{array}$ & $1.670(1.214-2.296)$ & .002 \\
\hline $\begin{array}{l}\text { Distance to treating facility } \\
\text { (continuous) }\end{array}$ & $1.000(0.999-1.001)$ & .136 \\
\hline \multicolumn{3}{|l|}{$\begin{array}{l}\text { Year of diagnosis (reference: } \\
\text { 2004-2008) }\end{array}$} \\
\hline 2009-2012 & $1.002(0.933-1.076)$ & .951 \\
\hline \multicolumn{3}{|l|}{$\begin{array}{l}\text { Clinical T classification } \\
\text { (reference: } \mathrm{T} 0 \text { ) }\end{array}$} \\
\hline $\mathrm{T} 1$ & $3.180(1.961-5.155)$ & $<.001$ \\
\hline $\mathrm{T} 2$ & $3.460(2.144-5.583)$ & $<.001$ \\
\hline $\mathrm{T} 3$ & $4.638(2.783-7.730)$ & $<.001$ \\
\hline
\end{tabular}

TABLE 2. Continued

\begin{tabular}{lcr}
\hline \multicolumn{1}{c}{ Parameter } & HR $(\mathbf{9 5} \%$ CI) & $\boldsymbol{P}$ value \\
\hline Histology (reference: biphasic) & & \\
$\quad$ Epithelioid & $0.577(0.422-0.788)$ & $<.001$ \\
Receipt of radiotherapy (yes vs no) & $0.839(0.610-1.154)$ & .280 \\
Induction chemotherapy (yes vs no) & $1.365(1.029-1.810)$ & $\mathbf{. 0 3 0}$ \\
\hline
\end{tabular}

Statistically significant $P$ values are shown in bold. $H R$, hazard ratio; $C I$, confidence interval.

database evaluated trends and outcomes in the 2 major management paradigms for resectable MPM, IC/R versus R/PC. IC/R use has been decreasing over time in the United States and is associated with regional- and facility-related factors. Although IC/R was associated with survival similar to $\mathrm{R} / \mathrm{PC}$, postoperative outcomes were worse with the former. Although careful patient selection is warranted when delivering IC for MPM, conclusions from these hypothesisgenerating data should remain incomplete until prospectively corroborated with an intention-to-treat analysis.

\section{Conflict of Interest Statement}

Authors have nothing to disclose with regard to commercial support.

\section{References}

1. National Comprehensive Cancer Network. Malignant pleural mesothelioma. Version 2.2018. Available at: https://www.nccn.org/professionals/physician_ gls/pdf/mpm.pdf. Accessed May 2, 2018.

2. Bovolato P, Casadio C, Bille A, et al. Does surgery improve survival of patient with malignant pleural mesothelioma? A multicenter retrospective analysis of 1365 consecutive patients. J Thorac Oncol. 2014:9:390-6.

3. Sugarbaker DJ, Gill RR, Yeap BY, et al. Hyperthermic intraoperative pleural cisplatin chemotherapy extends interval to recurrence and survival among lowrisk patients with malignant pleural mesothelioma undergoing surgical macroscopic complete resection. J Thorac Cardiovasc Surg. 2013;145:955-63.

4. Lang-Lazdunski L, Bille A, Belcher E, et al. Pleurectomy/decortication, hyperthermic pleural lavage with povidone-iodine followed by adjuvant chemotherapy in patients with malignant pleural mesothelioma. J Thorac Oncol. 2011;6:1746-52.

5. Zhu TC, Liang X, Kim MM, et al. An IR navigation system for pleural PDT. Front Phys. 2015;3:9.

6. Simone CB II, Cengel KA. Photodynamic therapy for lung cancer and malignant pleural mesothelioma. Semin Oncol. 2014;41:820-30.

7. Bech C, Sorensen JB. Chemotherapy-induced pathologic complete response in malignant pleural mesothelioma: a review and case report. J Thorac Oncol 2010;5:735-40.

8. Lau B, Kumar S, Yan T, et al. Pathological complete response in malignant pleural mesothelioma patients following induction chemotherapy: predictive factors and outcomes. Lung Cancer. 2017;111:75-8.

9. Van Schil P, Optiz I, Weder W, et al. Multimodal management of malignant pleural mesothelioma: where are we today? Eur Respir J. 2014;44:754-64.

10. Treasure T, Lang-Lazdunski L, Waller D, et al. Extra-pleural pneumonectomy versus no extra-pleural pneumonectomy for patients with malignant pleural mesothelioma: clinical outcomes of the Mesothelioma and Radical Surgery (MARS) randomised feasibility study. Lancet Oncol. 2011;12:763-72.

11. Casiraghi M, Maisonneuve P, Brambilla D, et al. Induction chemotherapy, extrapleural pneumonectomy and adjuvant radiotherapy for malignant pleural mesothelioma. Eur J Cardiothorac Surg. 2017;52:975-81.

12. Weder W, Stahel RA, Bernhard J, et al. Multicenter trial of neo-adjuvant chemotherapy followed by extrapleural pneumonectomy in malignant pleural mesothelioma. Ann Oncol. 2007;18:1196-202. 
13. Van Schil PE, Baas P, Gaafar R, et al. Trimodality therapy for malignant pleural mesothelioma: results from an EORTC phase II multicentre trial. Eur Respir J. 2010;36:1362-9.

14. Krug LM, Pass HI, Rusch VW, et al. Multicenter phase II trial of neoadjuvant pemetrexed plus cisplatin followed by extrapleural pneumonectomy and radiation for malignant pleural mesothelioma. J Clin Oncol. 2009;27:3007-13.

15. Stahel RA, Riesterer O, Xyrafas A, et al. Neoadjuvant chemotherapy and extrapleural pneumonectomy of malignant pleural mesothelioma with or without hemithoracic radiotherapy (SAKK 17/04): a randomised, international, multicentre phase 2 trial. Lancet Oncol. 2015;16:1651-8.

16. Clinicaltrials.gov. Pleurectomy/decortication (P/D) preceded or followed by chemotherapy in patients with early stage MPM. Available at: https:// clinicaltrials.gov/ct2/show/NCT02436733. Accessed May 2, 2018.

17. Bilimoria K, Stewart A, Winchester D, Ko C. The national cancer data base: a powerful initiative to improve cancer care in the United States. Ann Surg Oncol. 2008;15:683-90.

18. Verma V, Ahern CA, Berlind CG, et al. National cancer database report on pneumonectomy versus lung-sparing surgery for malignant pleural mesothelioma. $J$ Thorac Oncol. 2017;12:1704-14.

19. Verma V, Ahern CA, Berlind CG, et al. Facility volume and postoperative outcomes for malignant pleural mesothelioma: a national cancer data base analysis. Lung Cancer. 2018;120:7-13.

20. R Core Team (2017). R: a language and environment for statistical computing. R Foundation for Statistical Computing, Vienna, Austria. Available at: https:// www.R-project.org/. Accessed May 2, 2018.

21. Ho DE, Kosuke I, King G, Stuart EA. MatchIt: nonparametric preprocessing for parametric causal inference. J Stat Softw. 2011;42:1-28.

22. Austin PC. Optimal caliper widths for propensity-score matching when estimating differences in means and differences in proportions in observational studies. Pharm Stat. 2011;10:150-61.

23. Normand SL, Landrum MB, Guadagnoli E, et al. Validating recommendations for coronary angiography following an acute myocardial infarction in the elderly: a matched analysis using propensity scores. J Clin Epidemiol. 2001;54:387-98.

24. Marulli G, Faccioli E, Bellini A, Mammana M, Rea F. Induction chemotherapy vs post-operative adjuvant therapy for malignant pleural mesothelioma. Expert Rev Respir Med. 2017;11:649-60.
25. McMillan MT, Ojerholm E, Verma V, et al. Radiation treatment time and overall survival in locally advanced non-small cell lung cancer. Int J Radiat Oncol Biol Phys. 2017;98:1142-52.

26. Verma V, Ryckman JM, Simone CB II, Lin C. Patterns of care and outcomes with the addition of chemotherapy to radiation therapy for stage I nasopharyngeal cancer. Acta Oncol. 2018:57:257-61.

27. Verma V, Allen PK, Simone CB II, Gay HA, Lin SH. Association of treatment at high-volume facilities with survival in patients receiving chemoradiotherapy for nasopharyngeal cancer. JAMA Otolaryngol Head Neck Surg. November 2, 2017 [Epub ahead of print].

28. Verma V, Allen PK, Simone CB II, Gay HA, Lin SH. Addition of definitive radiotherapy to chemotherapy in patients with newly diagnosed metastatic nasopharyngeal cancer. J Natl Compr Canc Netw. 2017;15:1383-91.

29. Verma V, Surkar SM, Brooks ED, Simone CB II, Lin C. Chemoradiotherapy versus chemotherapy alone for unresected nonmetastatic gallbladder cancer: national practice patterns and outcomes. J Natl Compr Canc Netw. 2018;16:59-65.

30. Verma V, Simone CB II, Lin C. Human papillomavirus and nasopharyngeal cancer. Head Neck. 2018;40:696-706.

31. Ryckman JM, Kusi Appiah A, Simone CB II, Verma V. Treatment approaches for nasopharyngeal adenoid cystic carcinoma. Acta Oncol. 2018; 57:995-1001.

32. Verma V, Surkar SM, Moreno AC, Lin C, Simone CB II. Practice patterns and outcomes of chemoradiotherapy versus radiotherapy alone for older patients with nasopharyngeal cancer. Cancer Med. 2018;7:1604-11.

33. Ryckman JM, Lin C, Simone CB II, Verma V. Patterns of care for stage IA cervical cancer: use of definitive radiation therapy versus hysterectomy. Int J Gynecol Cancer. 2018;28:773-81.

34. Friedberg JS, Mick R, Culligan M, et al. Photodynamic therapy (PDT) and the evolution of a lung sparing surgical treatment for mesothelioma. Ann Thorac Surg. 2011;91:1738-45.

35. Friedberg JS, Simone CB II, Culligan MJ, et al. Extended pleurectomydecortication-based treatment for advanced stage epithelial mesothelioma yielding a median survival of nearly three years. Ann Thorac Surg. 2017;103:912-9.

Key Words: mesothelioma, pleural, chemotherapy, epithelioid, biphasic, surgery 
TABLE E1. Standardized mean differences between groups for each variable during propensity matching

\begin{tabular}{|c|c|}
\hline Parameter & $\begin{array}{c}\text { Standardized mean } \\
\text { difference }\end{array}$ \\
\hline \multicolumn{2}{|l|}{ Insurance type } \\
\hline Private & 0.14 \\
\hline Medicare & -0.16 \\
\hline Other government & 0.09 \\
\hline Uninsured & 0.00 \\
\hline Unknown & 0.00 \\
\hline \multicolumn{2}{|l|}{ Income (USD per year) } \\
\hline$<\$ 30,000$ & 0.07 \\
\hline$\$ 30,000-\$ 34,999$ & -0.21 \\
\hline$\$ 35,000-\$ 45,999$ & 0.18 \\
\hline$\geq \$ 46,000$ & -0.05 \\
\hline \multicolumn{2}{|c|}{$\begin{array}{l}\text { Percentage of adults in zip code } \\
\text { without high school diploma }\end{array}$} \\
\hline$\geq 21 \%$ & 0.04 \\
\hline $13 \%-20.9 \%$ & 0.00 \\
\hline $7 \%-12.9 \%$ & -0.12 \\
\hline$<7 \%$ & 0.10 \\
\hline \multicolumn{2}{|l|}{ Facility location } \\
\hline East north central & 0.00 \\
\hline East south central & -0.08 \\
\hline Middle Atlantic & -0.16 \\
\hline Mountain & 0.06 \\
\hline New England & 0.00 \\
\hline Pacific & 0.06 \\
\hline South Atlantic & 0.05 \\
\hline West north central & 0.00 \\
\hline West south central & 0.15 \\
\hline Facility type & 0.03 \\
\hline Distance to treating facility & 0.07 \\
\hline Year of diagnosis & -0.10 \\
\hline
\end{tabular}

